\title{
Transarterial Chemoembolisation Using Doxorubicin Beads for Unresectable Hepatocellular Carcinoma
}

\author{
Graeme J. Poston \\ Centre for Digestive Diseases, Aintree University Hospital, Liverpool, UK
}

The article by Sadick and colleagues [1] on TACE using doxorubicin (DC) beads for hepatocellular carcinoma (HCC) in this issue of Onkologie is timely. HCC is a major global healthcare problem and is increasing in incidence. Most patients still present at an advanced stage in their disease and few are ever considered candidates for potentially curative surgery (resection and/or liver transplantation). While some patients with small (sub-3 cm tumours) might benefit from radiofrequency ablation, for the vast majority, once diagnosed, treatment can only focus on palliation and best supportive care, effectively, there is no standard therapy for patients with unresectable HCC [2]. Although transarterial chemoembolisation (TACE) using conventional delivery of doxorubicin has been demonstrated to be effective in prolonging survival, only a small percentage of patients are thought fit enough to undergo such treatment [2]. Furthermore, treatment related complications are not uncommon with standard doxorubicin TACE, occurring in nearly $50 \%$ of cases [2]. Recent data have demonstrated a survival benefit for single agent sorafenib over placebo in patients with unresectable HCC in the presence of Child-Pugh grade A cirrhosis [3], but this remains an expensive treatment and beyond the ability of most developing health care systems to afford.

The major confounding factor when managing most $\mathrm{HCC}$ patients, and also in the design and execution of clinical trials in this condition, is the underlying liver disease that gave rise to the HCC [4]. Because of the problem posed by this background parenchymal liver disease, the American Association for the Study of Liver Disease (AASLD) recommend that in phase II trials investigating new treatment modalities in patients with incurable HCC, time to progression is probably the most valid and reproducible primary end point for such studies [4]. Furthermore, new drugs and delivery systems should be tested in patients with well preserved liver function (ChildPugh class A)[4].

\section{KARGER}

Fax +497614520714

Information@Karger.de

www.karger.com (c) 2010 S. Karger GmbH, Freiburg

Accessible online at:

www.karger.com/onk
Recent developments in embolic microsphere drug delivery offer an exciting opportunity for new avenues of treatment for non-resectable HCC [5-7]. The attraction of such an approach is the far greater precision in drug delivery, with the ability to deliver high dosages of cytotoxic chemotherapy within the arteriolar microvasculature of the tumour (and achieve a concomitant embolic tumour ischaemia), with the advantage of minimal systemic drug overspill and drug related co-morbidity [5-7]. Early clinical data seem promising, and although isolated treatment related deaths have still happened [8], overall treatment related morbidity seems to be significantly less than that seen following traditional TACE for HCC $[2,7,8]$. Although one always considers optimistic results of reported phase II trials with a degree of caution, both of these studies reported 12 month survival in excess of $90 \%$ and 2 year survival well above $80 \%$ [7, 8]. The present study by Sadick and colleagues [1], although retrospective in its analysis and on a similarly small patient population, reinforces the outcome data of the earlier reports, while treatment related adverse events remain relatively few. Interestingly, 8 of 14 patients who subsequently died following DC bead TACE, succumbed because of cirrhosis related hepatic failure, while their tumours remained stable.

Clearly, we need more data before DC bead TACE can be considered a standard of care for this diverse and heterogeneous group of patients. However, these early results are both interesting and promising and do need to be followed up. Currently a number of trial proposals are under discussion. This is probably most significant for patients whose disease is beyond resection or transplantation, in whom we should seek to examine the possible combination of DC bead TACE with systemic sorafenib. The second group of patients who may very well benefit from this treatment strategy are those on the waiting list for orthotopic liver transplantation, where DC bead TACE may offer a prolongation of the bridge to transplantation while 
awaiting a donor match. However, presently while these trials are underway the use of DC bead TACE to treat HCC should be restricted to tertiary centres with proven track records in the management of these patients. It would be extremely important to register these patients prospectively on a single unified registry in order to begin to identify which patients within this broad spectrum of disease gain the most benefit from this novel treatment. Lastly, such a register would capture data on patients initially considered unresectable, who might enjoy a sufficient partial response to such treatment to render them potential candidates for secondary surgical resection, a phenomenon now commonly seen in colorectal cancer metastatic to the liver, but never in primary HCC.

\section{Conflict of Interest}

No conflict of interests declared.

\section{References}

1 Sadick M, Haas S, Loehr M, Elshwi M, Singer MV Brade J, Schoenberg SO, Diehl SJ: Application of DC beads in hepatocellular carcinoma: clinical and radiological results of a drug delivery device for transcatheter superselective arterial embolization. Onkologie 2010;33: DOI: 10.1159/000264620.

2 Llovet J, Real MIA, Planas R, Coll S, Aponte J, Ayuso C, Sala M, Muchart J, Sola R, Rodes J, Bruix J: Arterial embolisation or chemoembolisation versus symptomatic treatment in patients with unresectable hepatocellular carcinoma: a randomised controlled trial. Lancet 2002;359:1734-39.

3 Llovet JM, Ricci S, Mazzoferro V, Hilgard P, Gane E, Blanc JF, de Oliveira AC, Santoro A, Raoul JL, Forner A, Schwartz M, Porta C, Zeuzem S, Bolondi L, Greten TF, Galle PR, Seitz JF, Borbath I, Haussinger D, Giannaris T, Shan M, Moscovici M, Voliotis D, Bruix J: Sorafenib in advanced hepatocellular carcinoma. New Engl J Med 2008;359:378-90.
4 Llovet JM, Di Bisceglie AM, Bruix J, Kramer BS, Lencioni R, Zhu AX, Sherman M, Schwartz M, Lotze M, Talwalkar J, Gores GJ: Design and endpoints of clinical trials in hepatocellular carcinoma. J Natl Cancer Inst 2008;100:698-711.

$\checkmark 5$ Lewis AL, Gonzalez V, Lloyd AW, Hall B, Tang Y, Willis SL, Leppard SW, Wolfenden LC, Palmer RR, Stratford PW: DC bead: in vitro characterization of a drug-delivery device for transarterial chemoembolization. J Vasc Int Radiol 2006;17:335-42.

6 Lewis AL, Taylor RR, Hall B, Gonzalez V, Willis SL, Stratford PW: Pharmacokinetics and safety studies of doxorubicin-eluting beads in a porcine model of hepatic artery embolization. J Vasc Int Radiol 2006; 17:1335-43.
7 Hong K, Khwaja A, Liapi E, Torbenson MS, Georgiades CS, Geschwind J-FH: New intra-arterial drug delivery system for the treatment of liver cancer: preclinical assessment in a rabbit model of liver cancer. Clin Cancer Res 2006;12:2563-7.

8 Varela M, Real MI, Burrel M, Forner A, Sala M, Brunet M, Ayuso C, Castells L, Montana X, Llovet JM, Bruix J: Chemoembolization of hepatocellular carcinoma with drug eluting beads: efficacy and doxorubicin pharmacokinetics. J Hepatol 2007;46: 474-81.

9 Malagari K, Alexopoulou E, Chatzimichael K, Hall B, Koskinas J, Ryan S, Gallardo E, Kelekis A, Gouliamos A, Kelekis D: Transcatheter chemoembolization in the treatment of HCC in patients not eligible for curative treatments: midterm results of doxorubicin-loaded DC beads. Abdom Imaging 2008;33:512-9. 